Original Research Paper

\title{
Modeling of Reinforced Concrete Frames with Infill Walls Under Cyclic Loading Strengthening with CFRP
}

\author{
${ }^{1}$ Mojtaba Fallahi, ${ }^{2}$ Sajjad Sayyar Roudsari, ${ }^{3}$ Mona Haghighifar and ${ }^{4}$ Rahmat Madandoost \\ ${ }^{1}$ M.Sc. in Structural Engineering, Islamic Azad University of Ahar, Ahar, Iran \\ ${ }^{2}$ Department of Computational Science and Engineering, \\ North Carolina A\&T State University, Greensboro, NC, USA \\ ${ }^{3}$ M.Sc. in Structural Engineering, University of Guilan, Rasht, Guilan, Iran \\ ${ }^{4}$ Department of Civil Engineering, Faculty of Engineering and Technology, University of Guilan, Rasht, Iran
}

Article history

Received: 20-03-2018

Revised: $12-05-2018$

Accepted: 4-07-2018

Corresponding Author

Mojtaba Fallahi

M.Sc. in Structural

Engineering, Islamic Azad

University of Ahar, Ahar, Iran

Email: mjtbcivil@gmail.com

\begin{abstract}
Nowadays, using infill isolators in Reinforced Concrete (RC) structures is very common. In earlier research this infill isolators are usually considered as non-structural elements, but in recent researches it was demonstrated that infill has considerable effects on natural period, stiffness, strength and overall behavior of structure specially when it is subjected to seismic ground motions. In this study a one-bay two-story masonry infilled $\mathrm{RC}$ frame is considered for a laboratory sample and various layouts of Carbon Fiber Reinforced Polymer (CFRP) layers have been used to retrofit and strengthen of masonry infill wall. These specimens have been modeled in ABAQUS and analyzed under cyclic loading with Finite Element Method (FEM). FEM analysis have been carried out using ABAQUS/Explicit software and analysis type have been chosen dynamic explicit. Finally, results of Finite Element Analysis have been compared against the experimental results. The effect of different CFRP configurations of retrofitting on ductility, ultimate lateral load capacity, stiffness and energy dissipation capacity of specimens have been discussed. Thereupon the best configuration has been proposed in terms of cost effectiveness and ductility. The results showed that in the frame with infill wall comparing with bare frame, load capacity increased about $277.35 \%$ and by comparing infilled frame with or without CFRP, it can be concluded that using CFRP can increase lateral load capacity of masonry infilled RC frames.
\end{abstract}

Keywords: Component RC Frame, CFRP, FEM Analysis, Infill Wall

\section{Introduction}

Earthquakes over a long time has been identified as the most destructive natural disasters in all over the world. Although there is no possibility of preventing earthquakes, new technologies in science and engineering may provide us with new devices to reduce their destructive effects. The common types of conventional buildings in urban areas is the unreinforced masonry wall, which fills the space between structural frames (El-Dakhakhni et al., 2006). Although, infill wall has been considered as non-structural component, the interactions between it and enclosing frame under seismic stimulation lead to undesired failure modes in the frame and infill walls (El-Dakhakhni et al., 2006). Generally, infill wall shows a poor performance in earthquakes and its behavior is usually brittle with low or no ductility and formability at all. In order to prevent this defect, several solutions have been proposed like grouting injection, installation of reinforcing steel, pretension, jacking and various reinforcement levels which cause increase in mass and stiffness of the structures but finally they impose more seismic loads on the structure.

In recent years, one of the state -of- the- art methods which has been considered by engineers is the retrofitting of existing structures using Fiber Reinforced Polymers (FRP). Due to lower thickness, higher resistance to weight ratio, higher stiffness and easy application using fiber reinforced polymers is an alternative method to retrofit the structures. In previous studies, researchers have used FRP layers in a variety of shapes such as strips and sheets to retrofit walls against seismic in-plane and out-of-plane loading (Ehsani et al., 1999; Triantafillou, 1998; Albert et al., 2001; Almusallam 
et al., 2001). In general, studies on the out-of-plane behavior of FRP reinforced masonry walls have shown that the use of FRP significantly increases the loading capacity of the walls. But, few researches have been done on the in-plane behavior of the FRP-reinforced walls.

El-Dakhakhni et al. (2004) evaluated seismic retrofitting of unreinforced concrete-masonry infilled steel frames using glass fiber reinforced polymer laminates under cyclic loading. Their experiments showed that attaching the Glass Fiber Reinforced Polymer (GFRP) layers on the masonry infill wall could increase the lateral load capacity of the infilled frame and stabilize walls surfaces to prevent the out of plane crushes on them. Erol and Karadogan (2016) did an investigation about the seismic strengthening of non-structural brittle masonry infill walls of reinforced concrete frames by Carbon Fiber Reinforced Polymers (CFRP). In this study, the effects of various application techniques on the lateral resistance and stiffness of infill wall was investigated analytically and experimentally. The results showed that there was a good agreement between experimental and numerical analysis. El-Diasity et al. (2015) did experimental tests on confined masonry walls retrofitted with ferrocement and GFRP systems under in-plane cyclic loading experimentally and analytically. Experimental results illustrated that the strengthening technique improved the lateral resistance, ductility and energy absorption of the panel. Akin et al. (2011) retrofitted 8 reinforced concrete frames; one frame by two stories with two different ratio dimensions, 1.3 scales with (CFRP) carbon fiber reinforced polymer layers and tested under cyclic loading condition. By applying the retrofitting method, the load capacity of the samples significantly increased. Retrofitting with CFRP significantly increased energy dissipation capabilities of the samples without ratio of dimensions. Soleimani and Sayyar Roudsari (2015) had investigation on RC beams under impact loading condition by ABAQUS software in different height and velocity of hammer. The range of height was from $400 \mathrm{~mm}$ to $2000 \mathrm{~mm}$. He also retrofitted two samples with GFRP sheets and reinforced with GFRP and CFRP bars in order to compare the behavior of RC beams. The outputs showed that by increasing the height of hammer decreased the load capacity. Also, using GFRP bars had better performance for improving ductility than GFRP sheets and CFRP bars had the higher load capacity than all other samples. Sakr et al. (2017) investigated the behavior of CFRP retrofitted infilled RC frames with a finite element micro model. They used a four nodes shell element for modeling of the concrete, infill panel and CFRP sheets. The results indicated that, to get the highest efficiency of the CFRP strengthened infilled frame, 25\% of the diagonal length bonding from both ends is efficient to get the same behavior of the totally bonded sheet. Babatunde (2017) carried out numerical calculations using finite element method on strengthening of masonry walls under in-plane loading. Two types of cross and grid configurations of FRP were used to retrofit the walls. Results showed that static behavior of the wall was improved because of the role of FRP sheets in transmitting tensile stresses from masonry to the sheets.

\section{Sample Specification of Laboratory Model}

In this study, the samples used for the modeling are of the experiments carried out by Ozcebe et al. (2003). The tested concrete frames have the following defects:

1. Insufficient confinement at the end regions of the beams and columns

2. Inappropriate connections in transverse reinforcement

3. Insufficient anchorage length of bottom rebar in the beams

4. Low compressive strength of concrete Ozcebe et al. (2003)

Samples tested in this study are two-stories which are connected to a rigid foundation beam and they tested in horizontal position. The ties in beams and columns of frame were used every $100 \mathrm{~mm}$. No confinement was provided at member ends by decreasing the tie spacing.

The ends of the ties had at $90^{\circ}$ bents and were overlapped at the corner. In addition, there were no ties beam column joints.

Since lapped splices made in columns longitudinal bars at floor levels are known to reduce the strength of infilled frames, (Sonuvar, 2001) no splices were made at the base of first story columns at the foundation level. However longitudinal bars in columns of the second story had lapped splices at the base.

The lap length was $300 \mathrm{~mm}$ (about 38 bar diameters). Reinforcement and dimensions of the test specimen are shown in Fig. 1.

In this study, 11 frame samples were considered and nonlinear finite element analysis were carried out by ABAQUS software and the results were compared with experimental results. The first sample is a one-bay, twostory reinforced concrete frame without infill wall. Figure 1 illustrates reinforcement details and dimensions of the RC frame and the other samples are the same as the first sample, except that they were infilled with bricks in both stories. Nine frames have been retrofitted with CFRP. Unretrofitted frames (hollow frame and infilled frame) are considered as reference samples. The foundation beam of the frame was constructed monolithically and the foundation was heavily reinforced to prevent local failures. Moreover the ties were bent 135 degree into the core to ensure the confinement (Fig. 2). Moreover, two longitudinal mid-rebars were provided in the concrete frame:

1. Longitudinal bars $\varphi 8$, Ties $\varphi 4 / 50 \mathrm{~mm}$

2. All dimensions in $\mathrm{mm}$ 
Mojtaba Fallahi et al. / American Journal of Engineering and Applied Sciences 2018, 11 (3): 1086.1099 DOI: 10.3844/ajeassp.2018.1086.1099

Table 1: Specifications for samples (Ozcebe et al., 2003)

Samples Infill walls $\quad$ Reinforced with FRP

$$
1
$$

2 $\square$

$\square$

3

口

口

4

口

$\square$

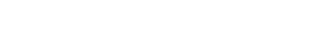

5

6

7

a

$\square$

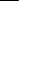

8

9

10

11
2

2

Number of reinforced layers

Reinforced model

-

$$
\text { ए }
$$

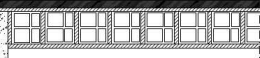

- CFRP

Mortar \& Plaster
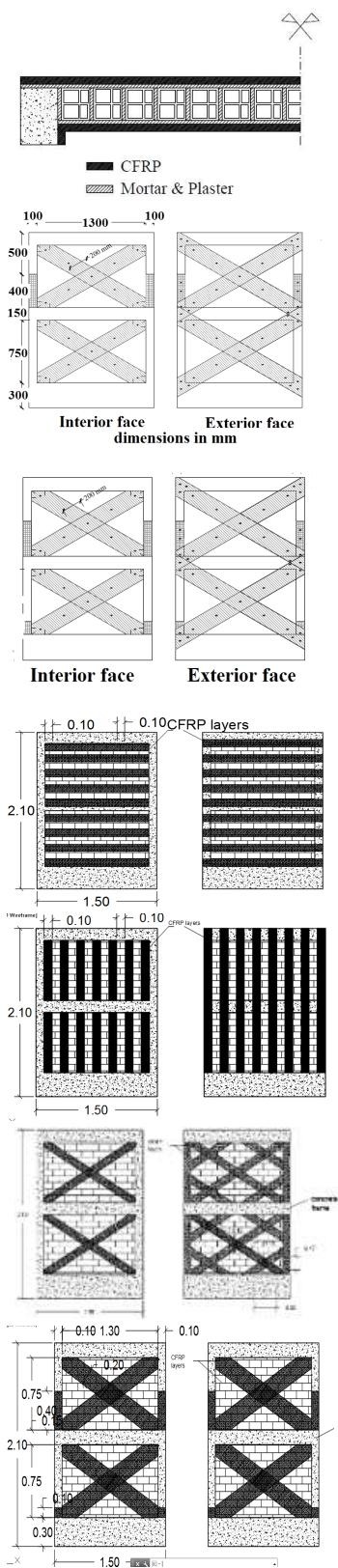


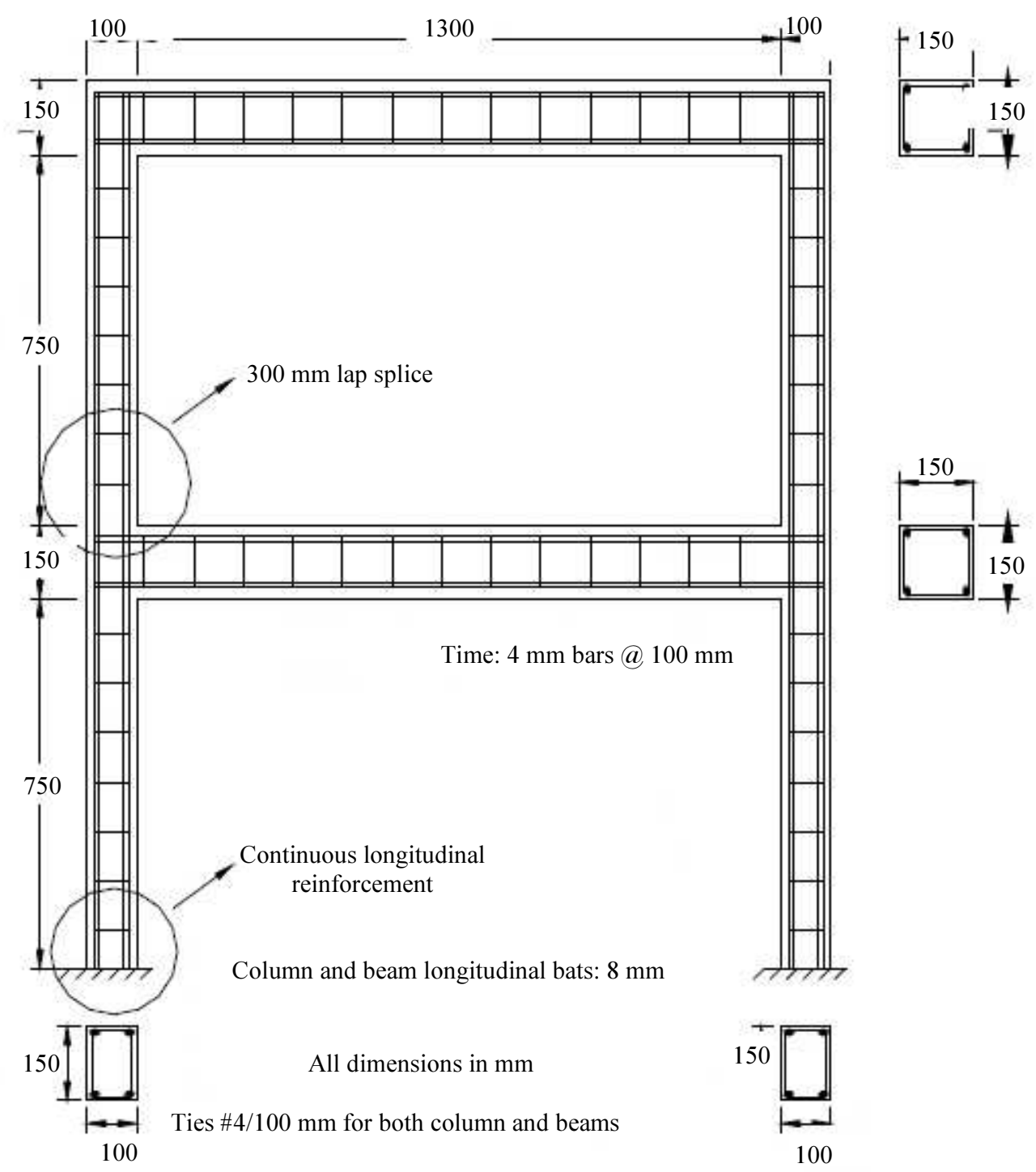

Fig. 1: Section Specifications and Details of RC Frame (Ozcebe et al., 2003)
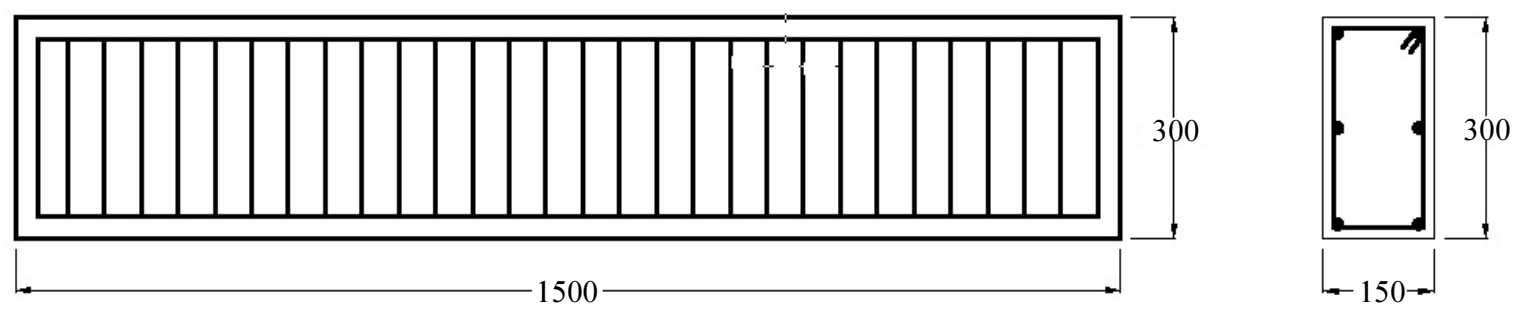

Fig. 2: Reinforcement of the beam (Ozcebe et al., 2003)

Hollow clay brick was used as in infill walls. In order to simulate the actual brick, the standard bricks with a size of $18 \times 18 \times 8.5 \mathrm{~cm}$ were cut into four smaller bricks with dimensions of $9 \times 7.5 \times 8.5 \mathrm{~cm}$ (Fig. 3).
The mortar between the bricks was made by mixing sand, cement, lime and water. The tiles were laid when the specimen was placed in a vertical position. Infill brick was plastered on both sides with a plaster layer of $10 \mathrm{~mm}$ thickness. The samples are according to Table 1. 


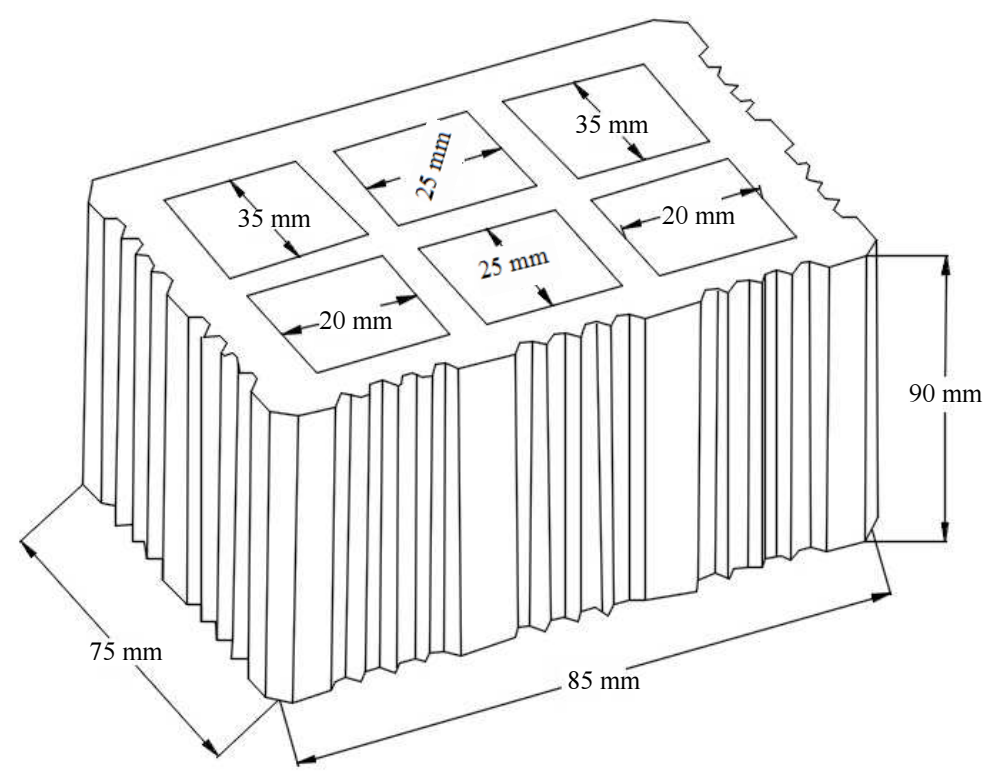

Fig. 3: Dimensions of hollow bricks (Ozcebe et al., 2003)

\section{Finite Element Model}

For modeling of Concrete, 8-node three-Dimensional element with Reduced integration (C3D8R) was used. The type of element used for reinforcement was B31, which is a type of elements of a 3-dimensional beam with a linear (first degree) function and the stirrups were modeled as a rectangular shape without bending performance, because in this modeling the bending effect of rebars are not considered. For masonry materials, the element used for concrete modeling, namely C3D8R was selected. It should be noted that, the bricks were considered as a micro model which means that each brick must be assembled individually. For modeling FRP, shell elements of a linear (first degree) function and reduced integration (S4R) were used. The embedded region was used to model interaction between concrete and rebar. Also, the surface contacts between the fibers and the concrete was considered by using tie constraint.

In addition, the brick and RC frame were considered as solid element and the interaction between them is defined by tie and the concrete is applied master and brick is slave. Moreover, the thickness of CFRP is considered $0.5 \mathrm{~mm}$.

In this study, due to static loadings condition, a nonlinear static method was used for analysis first, but on the grounds of the weakness of this method, concrete analysis was excluded in the nonlinear range. In fact, the main problem of this method is divergent behavior in the nonlinear range and failure in analysis. Therefore, because of the brittle and highly nonlinear behavior of the materials, eventually the dynamic explicit method was selected. The results should be monitored to ensure accuracy and stability, so the analysis hypotheses are as follows:
1. The lateral forces are applied to the structure on the second-floor level. But in real structure, earthquake's force is not so simple

2. The loading is dynamic. FEM analysis has been carried out using ABAQUS/Explicit software and analysis type was chosen dynamic explicit (ABAQUS, 2012)

3. Structures are tested in horizontal conditions. Therefore, in modeling and analysis, their weight is also neglected

4. The axial load applied to each column is equal to 60 $\mathrm{KN}$, which is applied to the top of each column. To avoid stress concentration on the top of columns, two steel plates were attached to top of columns

5. Lateral loading is a type of displacement control that is the same for all specimens. The history of this type of loading is shown in Fig. 5

The average compressive strength of the concrete for samples is considered to be $19.5 \mathrm{MPa}$ (Ozcebe et al., 2003). There are various equations to determine the modulus of elasticity of concrete based on the compressive strength. Here the ACI-318 equation (ACI1988) is used for this purpose:

$E_{c}=15000 \sqrt{f_{c}^{\prime}}\left(\frac{\mathrm{kg}}{\mathrm{cm}^{2}}\right)=15000 \sqrt{19500} \cong 21 G p a$

The Poisson ratio of Concrete is 0.2. Concrete Damaged Plasticity was used to model concrete plasticity characteristics to software. The model is a continuum, plasticity-based, damage model for concrete. It assumes that the main two failure mechanisms are tensile cracking and compressive crushing of the concrete material. The evolution of the yield (or failure) 
surface is controlled by two hardening variables $\tilde{\varepsilon}_{c}^{p l}$ and $\tilde{\varepsilon}_{c}^{p l}$ linked to failure mechanisms under tension and compression loading, respectively. We refer to $\tilde{\varepsilon}_{c}^{p l}$ and $\tilde{\varepsilon}_{c}^{p l}$ as tensile and compressive equivalent plastic strains, respectively (ABAQUS, 2012). The concrete damaged plasticity model can be very appropriate to any kind of loading condition specially in the term of dynamic loading (Roudsari et al., 2018). It should be noted that the failure criterion and yield function of this damage model is Drucker and Prager (1952) and Lubliner et al. (1989) respectively.

To define the uniaxial behavior curve of uncofined concrete, we can use experimental results or use existing behavioral models in this field. In this study, one of the most popular unconfined concrete behavior models namely Kent and Park (1971) was used. The relation of this model is as follows:

$$
\sigma_{c}=f_{c o}^{\prime}\left(\frac{2 \varepsilon}{\varepsilon_{c}^{\prime}}-\left(\frac{\varepsilon_{c}}{\varepsilon_{c}^{\prime}}\right)^{2}\right)
$$

In the above equation, $\sigma_{c}$ and $\varepsilon_{c}$ are compressive stress and strain, $f_{c o}^{\prime}$ and $\varepsilon_{c}^{\prime}$, are the compressive strength of the cylindrical sample of the unconfined concrete and the corresponding strain respectively. Park et al. (1975) reported the value of $\varepsilon_{c}^{\prime}$ as 0.002 and in this study it is considered as 0.002 too (ACI, 1988). The micro model method has been used for modeling the masonry building materials. In this model, expanded bricks have modeled individually and there are contact between the bricks and their stiffness properties are dependent on the properties of the mortar Pour Aminian (2008). The compressive strength of the masonry materials is $20.6 \mathrm{MPa}$, its modulus of elasticity is 6534 $\mathrm{MPa}$ and its breaking strain is equal to 0.0057 (Kaushik et al., 2007). To define the brick, we also use a concrete damage plasticity model. The parameters of this model are default and only dilation angle should be changed. The degree of internal dilation of masonry materials is negligible and in significant overheads it is zero (Shahbazi and Yekrang Nia, 2013), Table 2.

Since the blocks used are hollow, the most precise method is to define the properties of bricks in two directional form. On the other hand, since the behavior of bricks in many walls is influenced by their vertical side properties, it can be considered as isotropic with the assumption of simplifying materials.

To determine the interaction between bricks, two behaviors are used:

1. Adhesion in shear and tensile phases

2. Friction in the shear phase

To define adhesion behavior, it is necessary to define the stiffness values of the mortar in the direction of vertical (tensile), the shear in the $x$ direction in the general coordination system and shear in axis $y$ direction. The variables related must be defined to the creation and evolution of failure in the adhesion phase. Thus, the tensile strength, shear in the direction of 1 total coordinate and shear direction 2 are respectively 61.1 $\mathrm{MPa}, 93.350 \mathrm{MPa}$ and $93.350 \mathrm{MPa}$, which is equal to the second and third variables due to the isotropic content of the mortar. Damage to the cohesive element can be exploited by exponential damage. Modeling details of infilled frame have been provided in Fig. 4 which shows that the structure was protected against out-of-plane deflection by using of roller supports.

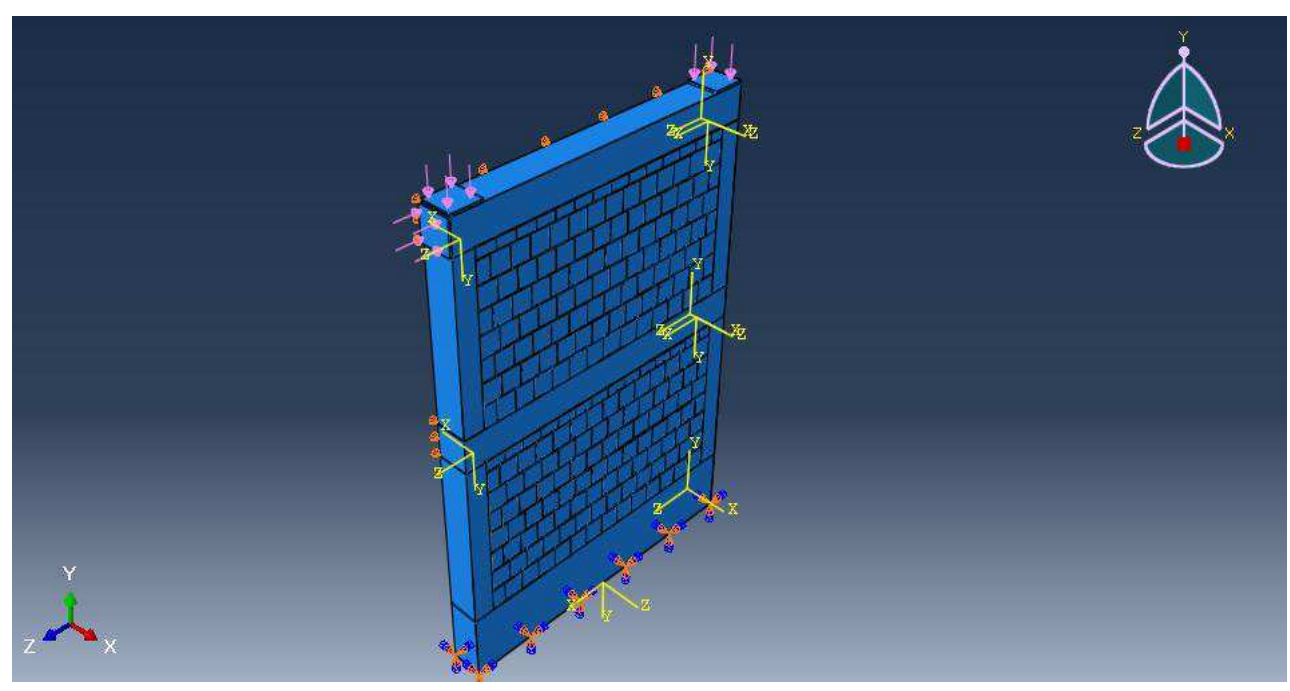

Fig. 4: Modeling details in the software 


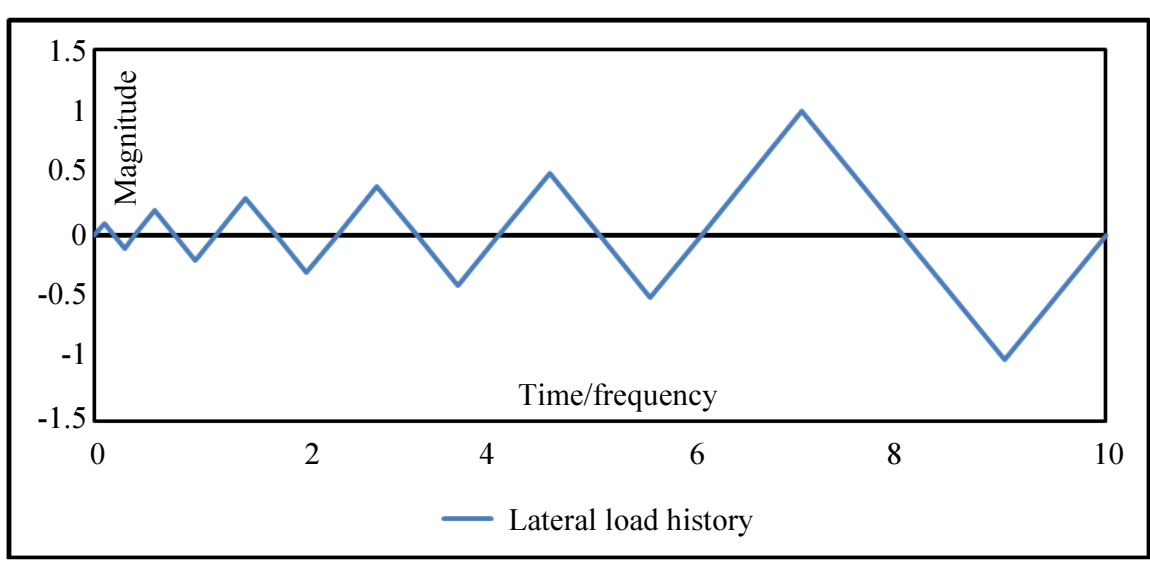

Fig. 5: Lateral load history for finite element analysis

Table 2: Specifications of plastic masonry materials (Shahbazi and Yekrang Nia, 2013)

\begin{tabular}{lllll}
\hline Angle of expansion & Eccentricity & $\mathrm{fb} 0 / \mathrm{fc} 0$ & $\mathrm{~K}$ & viscosity \\
\hline 10 & 0.1 & 1.16 & 0.67 & 0.001 \\
\hline
\end{tabular}

Table 3: Mechanical Properties of FRP Composites (Kachlalev and Miller, 2001)

\begin{tabular}{llllll}
\hline $\begin{array}{l}\text { Composite } \\
\text { type }\end{array}$ & $\begin{array}{l}\text { Elasticity } \\
\text { Modulus (MPa) }\end{array}$ & $\begin{array}{l}\text { Maximum } \\
\text { Poisson's ratio }\end{array}$ & $\begin{array}{l}\text { Tensile } \\
\text { strength (MPa) }\end{array}$ & $\begin{array}{l}\text { Shear } \\
\text { modulus (MPa) }\end{array}$ & $\begin{array}{l}\text { Layer } \\
\text { thickness (mm) }\end{array}$ \\
\hline CFRP & $E_{x}=62000$ & $v_{x y}=0.22$ & 958 & $G_{x y}=3270$ & 1.0 \\
& $E_{y}=4800$ & $v_{x z}=0.22$ & & $G_{x z}=3270$ & \\
& $E_{z}=4800$ & $v_{y z}=0.30$ & & $G_{y z}=1860$ & \\
\hline
\end{tabular}

Table 4: variables of damage to FRP (Kachlalev and Miller, 2001)

\begin{tabular}{llllll}
\hline $\begin{array}{l}\text { Shear strength } \\
\text { transverse (MPa) }\end{array}$ & $\begin{array}{l}\text { Shear strength } \\
\text { longitudinal }(\mathrm{MPa})\end{array}$ & $\begin{array}{l}\text { Compressive strength } \\
\text { transverse }(\mathrm{MPa})\end{array}$ & $\begin{array}{l}\text { Tensile strength } \\
\text { Transverse (MPa) }\end{array}$ & $\begin{array}{l}\text { Compressive strength } \\
\text { longitudinal (MPa) }\end{array}$ & $\begin{array}{l}\text { Tensile strength } \\
\text { Longitudinal (MPa) }\end{array}$ \\
\hline 48 & 96 & 74 & 74 & 958 & 958 \\
\hline
\end{tabular}

In this study, CFRP mass density is considered to be $1800 \mathrm{~kg} / \mathrm{m}^{3}$. Also, the materials will have a high resistance in a single direction and in a longitudinal direction (local axis $\mathrm{x}$ ). In this way, the materials can be defined by the behavior of a plate stress and with different properties in different directions. To determine the mechanical properties of FRP in different directions, it is necessary to carry out standard tests on the materials. Here, it has been used the specification values of (Kachlalev and Miller, 2001) Table 3 and 4.

It also should be noted that, the bricks were interacted with each other using general contact method and the sides of bricks which were contacted with RC elements were tied. In other word, the Tie parameter is used by defining the RC surface as a master and the brick as slave surface. Moreover, the FRP thickness for all models is $0.5 \mathrm{~mm}$.

\section{Discussion}

Due to the significant time needed for analysis, special measures were taken to reduce the analysis time, including mass scaling and incremental increase. Also because of some fluctuations which was created in force and displacement diagrams in dynamic explicit analysis, special filters were applied to diagram requests before analysis. One of these filters was Anitialising, which was applied to requests of displacement and forces. Also, at the end of the analysis, Smooth functions were used to minimize fluctuations. In order to verify the accuracy of the modeling, the concrete frame mentioned in the sample 2 was analyzed and compared with the experimental results. In the figures below, the loaddisplacement hysteresis curve compared to displacement of the first floor for the experimental and the finite element models.

As shown in Fig. 6, there is a good agreement between numerical modeling and experimental results and the difference between the graphs is about $5 \%$ and this acceptable difference indicates that the modeling method is accurate.

The sample of 1 is a frame without infill wall. Figure 7 showed hysteresis curve (cycles) Load-displacement of sample 1. The load capacity is approximately $15 \mathrm{KN}$, which is very weak. The sample of 2 is a frame with infill wall. Figure 8 showed hysteresis curve (cycles) 
Load-displacement of sample 2. The addition of infill wall leads to improved bearing capacity. The load capacity is $60 \mathrm{KN}$. The initial stiffness is from 1879 to $28169 \mathrm{KN} / \mathrm{m}$. The amount of drift is decreased and the energy lost is increased. The sample of 3 is the first retrofit Infill wall. Figure 9 showed hysteresis curve (cycles) Load-displacement of sample 3. The max energy lost is significant and the value is $22.5 \mathrm{KN} . \mathrm{m}$. In sample 4, the addition of CFRP increased tensile damage. The addition hysteresis curve (cycles) loaddisplacement of sample 10. This sample strengthening is shown in Table 1. The load capacity is approximately $125 \mathrm{KN}$. The addition of CFRP leads to improved bearing capacity. The load capacity is $100 \mathrm{KN}$. Figure 10 showed hysteresis curve (cycles) Load-displacement of sample 4. Figure 11 showed hysteresis curve (cycles) load-displacement of sample 5. The load capacity is approximately $170 \mathrm{KN}$, which is very hard. The max energy lost value is $18 \mathrm{KN}$.m. In this sample, one side of the frame is completely covered with CFRP. Figure 12 showed hysteresis curve (cycles) Load-displacement of sample 6. In sample 6 the infill wall strengthening with diagonally CFRP. The load capacity is approximately $115 \mathrm{KN}$. The max energy lost value is $10 \mathrm{KN}$.m. The sample of 7 is similar to sample of 6 . Figure 13 showed hysteresis curve (cycles) Load-displacement of sample 7. In sample 7 the infill wall strengthening with diagonally CFRP. The load capacity is approximately $120 \mathrm{KN}$. The max energy lost value is 20 KN.m. Figure 14 showed hysteresis curve (cycles) Load-displacement of sample 8. The used of horizontal CFRP has low effect of bearing capacity. Figure 15 showed hysteresis curve (cycles) load-displacement of sample 9. Using vertical stripes are more effective than horizontal stripes.

Table 5: Summary of finite element analysis results

\begin{tabular}{lllrl}
\hline Sample no. & Max lateral forces $(\mathrm{KN})$ & Initial stiffness $(\mathrm{KN} / \mathrm{m})$ & Max energy lost (KN.m) & Max drft (story1) \\
\hline 1 & 15.9 & 1879 & 0.26 & 0.0230 \\
2 & 60.0 & 28169 & 5.50 & 0.0200 \\
3 & 54.0 & 41322 & 22.50 & 0.0128 \\
4 & 99.6 & 39793 & 12.00 & 0.0106 \\
5 & 170.0 & 44437 & 18.00 & 0.0181 \\
6 & 113.7 & 40098 & 10.00 & 0.0104 \\
7 & 120.5 & 41651 & 20.00 & 0.0100 \\
8 & 76.0 & 10300 & 5.00 & 0.0302 \\
9 & 103.8 & 14459 & 6.50 & 0.0310 \\
10 & 124.7 & 12741 & 5.00 & 0.0270 \\
11 & 145.0 & 37023 & 2.00 & 0.0106
\end{tabular}

Table 6: Floors loads and displacements for each sample

\begin{tabular}{|c|c|c|c|c|c|}
\hline Sample no. & Floors & $\begin{array}{l}\text { Maximum lateral } \\
\text { loads }(\mathrm{N})\end{array}$ & $\begin{array}{l}\text { Minimum lateral } \\
\text { loads }(\mathrm{N})\end{array}$ & $\begin{array}{l}\text { Maximum } \\
\text { displacement (m) }\end{array}$ & $\begin{array}{l}\text { Minimum } \\
\text { displacement (m) }\end{array}$ \\
\hline \multirow[t]{2}{*}{1} & 1 & 16958.7 & -16041.0 & 0.0178 & -0.02110 \\
\hline & 2 & 16023.4 & -15555.6 & 0.0394 & -0.04040 \\
\hline \multirow[t]{2}{*}{2} & 1 & 55449.7 & -60529.1 & 0.0229 & -0.01450 \\
\hline & 2 & 54782.6 & -62608.7 & 0.0626 & -0.09290 \\
\hline \multirow[t]{2}{*}{3} & 1 & 49595.4 & -55144.5 & 0.0082 & -0.00950 \\
\hline & 2 & 49450.5 & -54065.9 & 0.0184 & -0.01260 \\
\hline \multirow[t]{2}{*}{4} & 1 & 99127.9 & -84011.6 & 0.0081 & -0.00810 \\
\hline & 2 & 9830.4 & -83918.1 & 0.0215 & -0.01390 \\
\hline \multirow[t]{2}{*}{5} & 1 & 82352.9 & -171764.7 & 0.0057 & -0.01360 \\
\hline & 2 & 80588.2 & -170000.0 & 0.0217 & -0.01960 \\
\hline \multirow[t]{2}{*}{6} & 1 & 114248.7 & -106476.7 & 0.0058 & -0.00780 \\
\hline & 2 & 113101.6 & -106648.5 & 0.0159 & -0.01140 \\
\hline \multirow[t]{2}{*}{7} & 1 & 120348.8 & -99418.6 & 0.0075 & -0.00645 \\
\hline & 2 & 119318.2 & -98863.6 & 0.0186 & -0.00990 \\
\hline \multirow[t]{2}{*}{8} & 1 & 69846.2 & -76000.0 & 0.0240 & -0.02200 \\
\hline & 2 & 69514.6 & -76407.8 & 0.0440 & -0.04200 \\
\hline \multirow[t]{2}{*}{9} & 1 & 104594.6 & -94864.9 & 0.0250 & -0.02200 \\
\hline & 2 & 102717.4 & -94565.2 & 0.0348 & -0.03410 \\
\hline \multirow[t]{2}{*}{10} & 1 & 122088.9 & -129798.4 & 0.0208 & -0.01680 \\
\hline & 2 & 124242.4 & -127272.7 & 0.0343 & -0.03290 \\
\hline \multirow[t]{2}{*}{11} & 1 & 142857.1 & -145054.9 & 0.0140 & -0.00803 \\
\hline & 2 & 142857.1 & -140659.3 & 0.0240 & -0.02290 \\
\hline
\end{tabular}


Figure 16 showed the max energy lost value is 5 KN.m. Figure 17 showed hysteresis curve (cycles) loaddisplacement of sample 11. This sample strengthening is shown in Table 1. The load capacity is approximately $145 \mathrm{KN}$. The max energy lost value is 2 KN.m. The sample width is more than sample 10 .

Table 5 showed the summary of finite element analysis. By comparing the hysteresis curves of samples
1 and 2, it can be concluded that in the case of infill wall, the specimen 2 has an increase in the bearing capacity in the first and second floors, respectively, by $69.41 \%$ and $70.75 \%$ compared without infill wall. This indicates that infill wall increases capacity load. Also, the degree of ductility (displacement) of sample 2 compared to sample 1 in the first and second story respectively increased to $22.35 \%$ and $37.06 \%$.

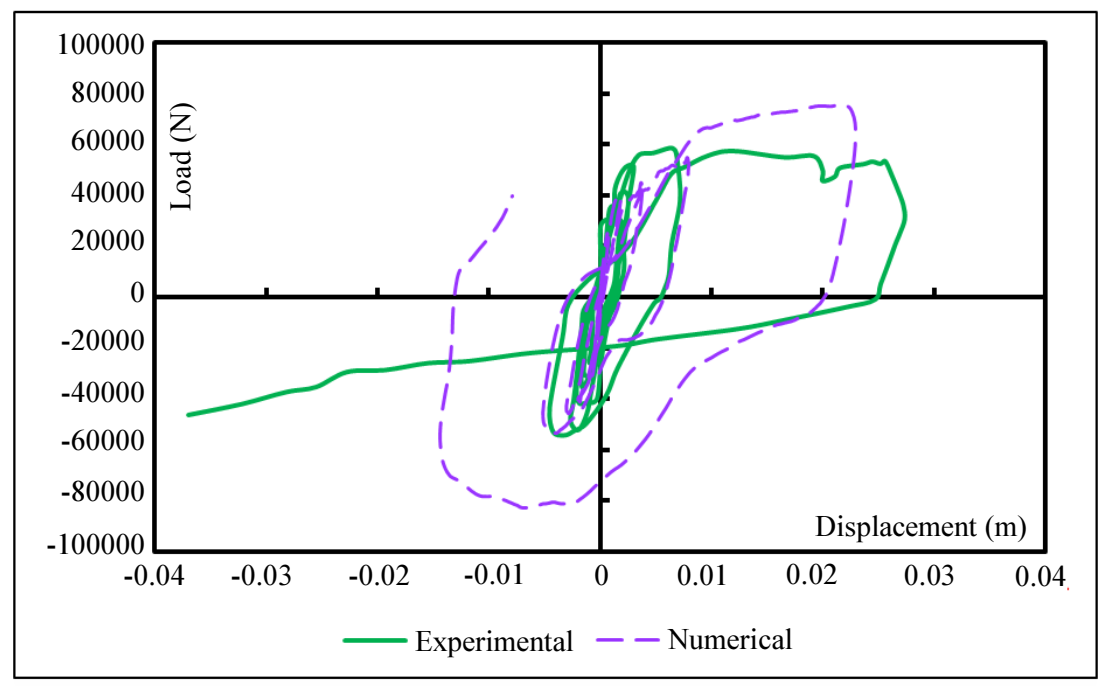

Fig. 6: Comparison between Hysteresis Curves of Experimental and Finite Element analysis
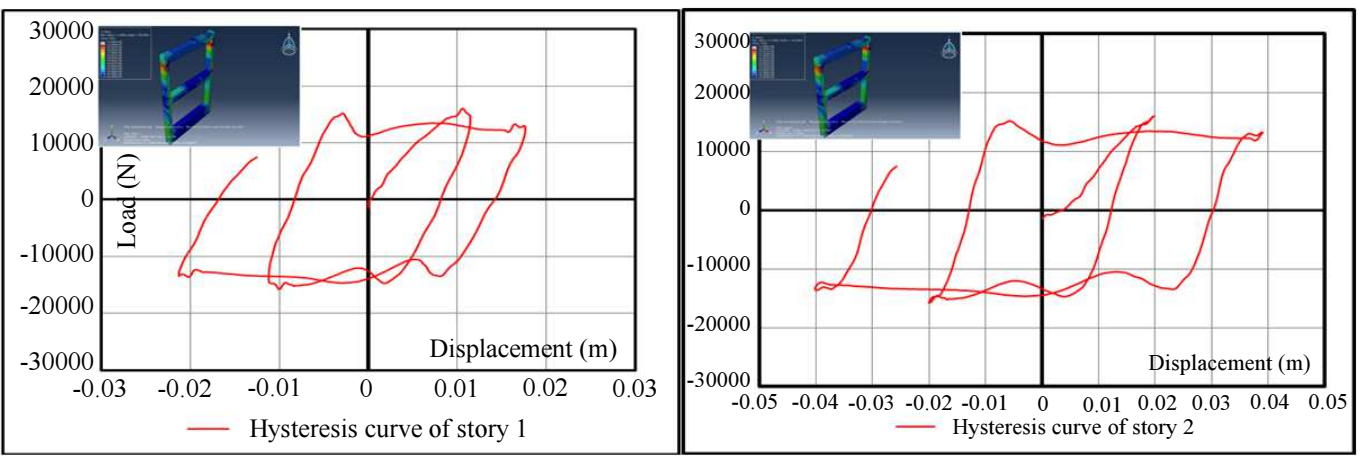

Fig. 7: Hysteresis curve (cycles) of displacement of sample 1
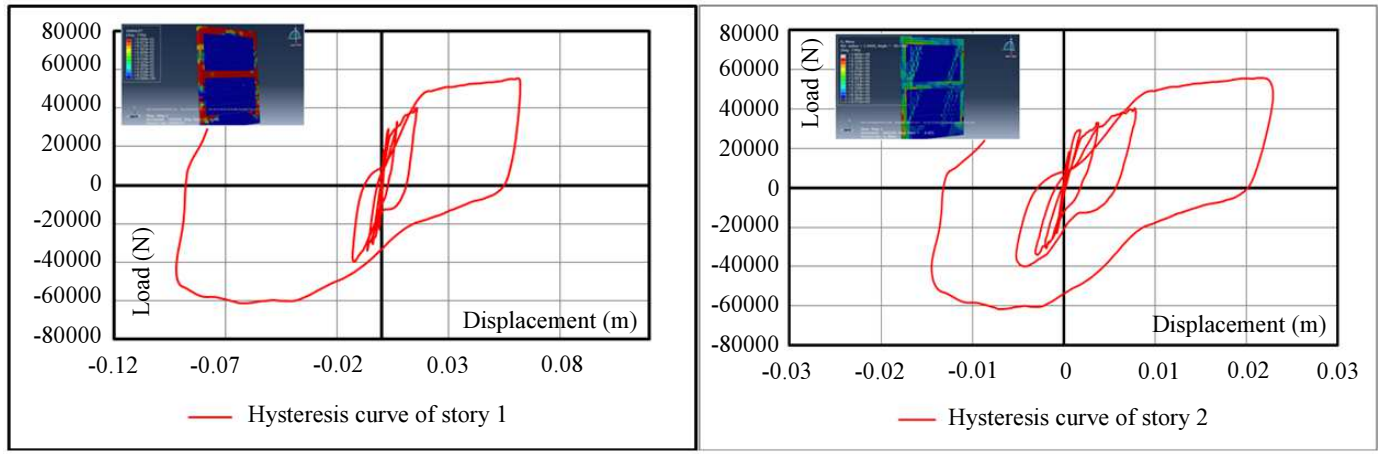

Fig. 8: Hysteresis curve (cycles) of displacement of sample 2 


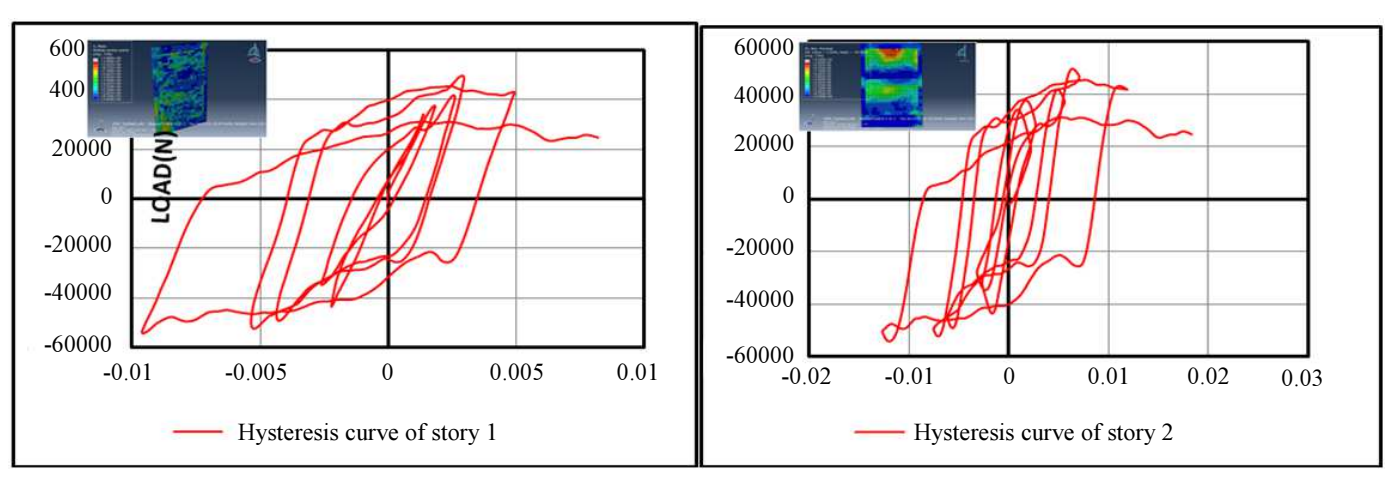

Fig. 9: Hysteresis curve (cycles) of displacement of sample 3

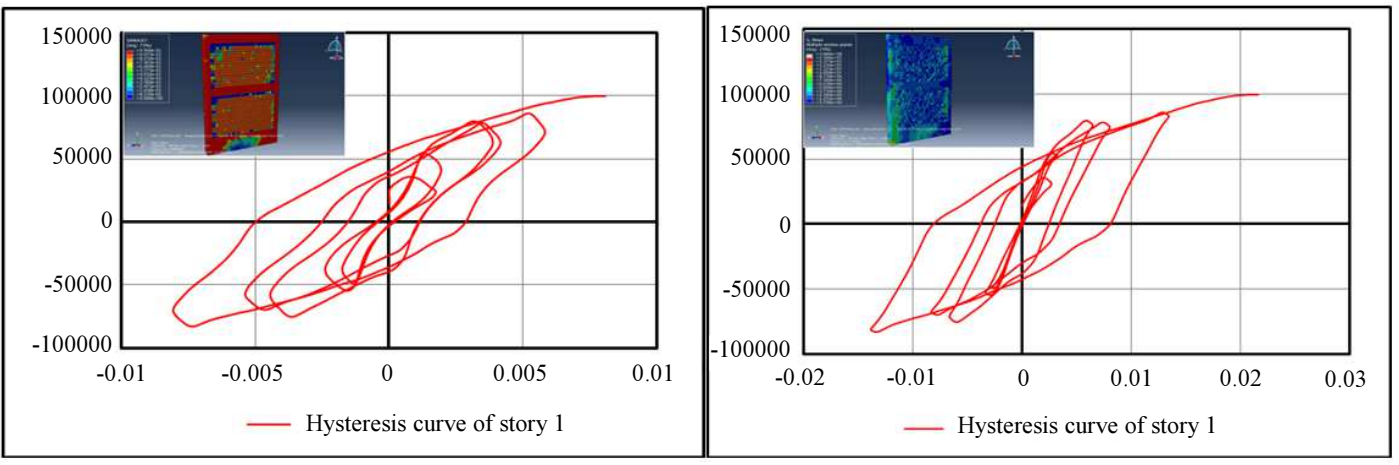

Fig. 10: Hysteresis curve (cycles) of displacement of sample 4
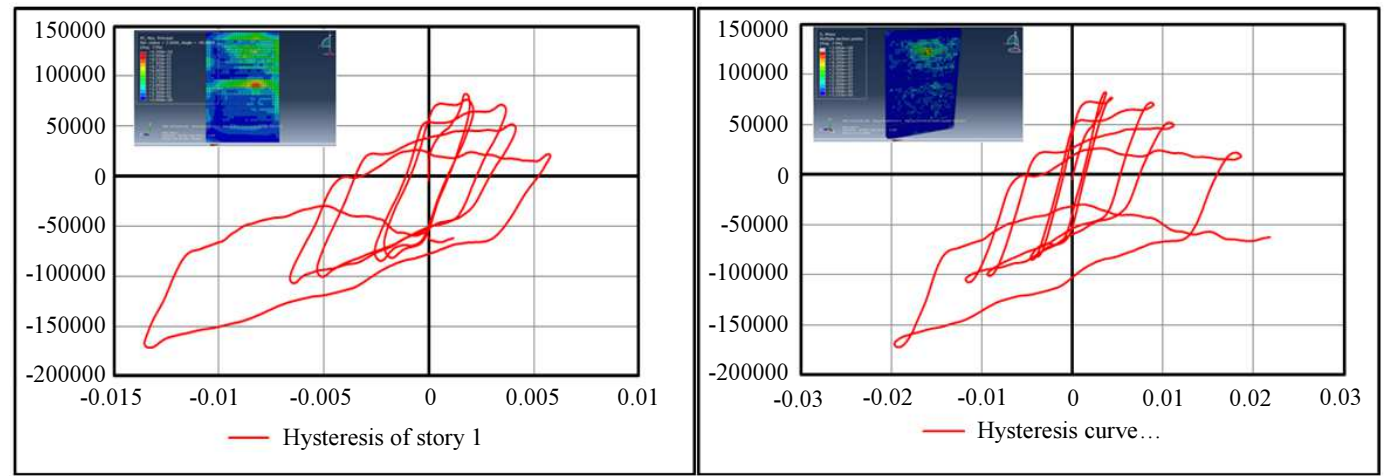

Fig. 11: Hysteresis curve (cycles) of displacement of sample 5
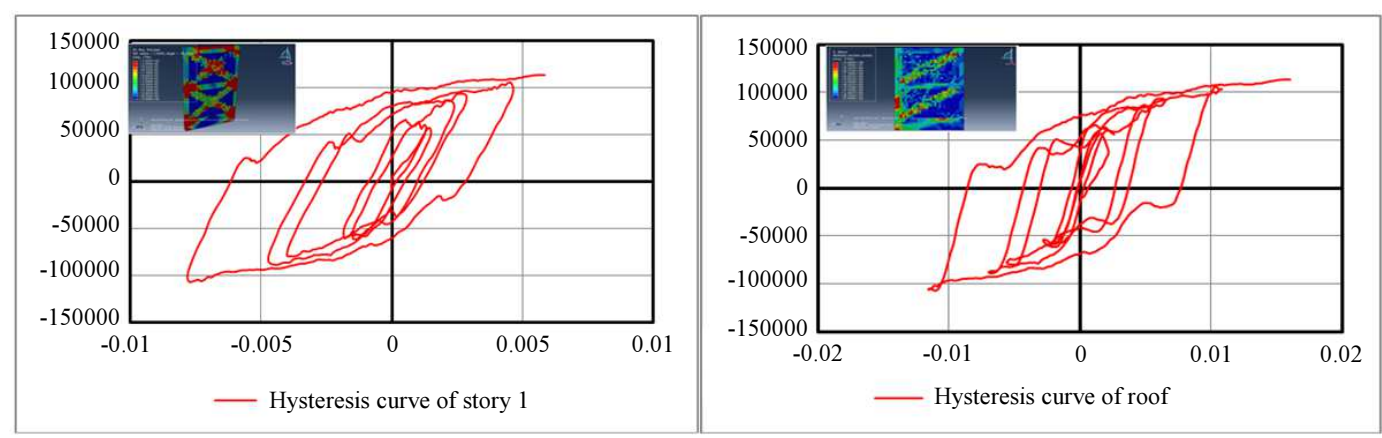

Fig. 12: Hysteresis curve (cycles) of displacement of sample 6 


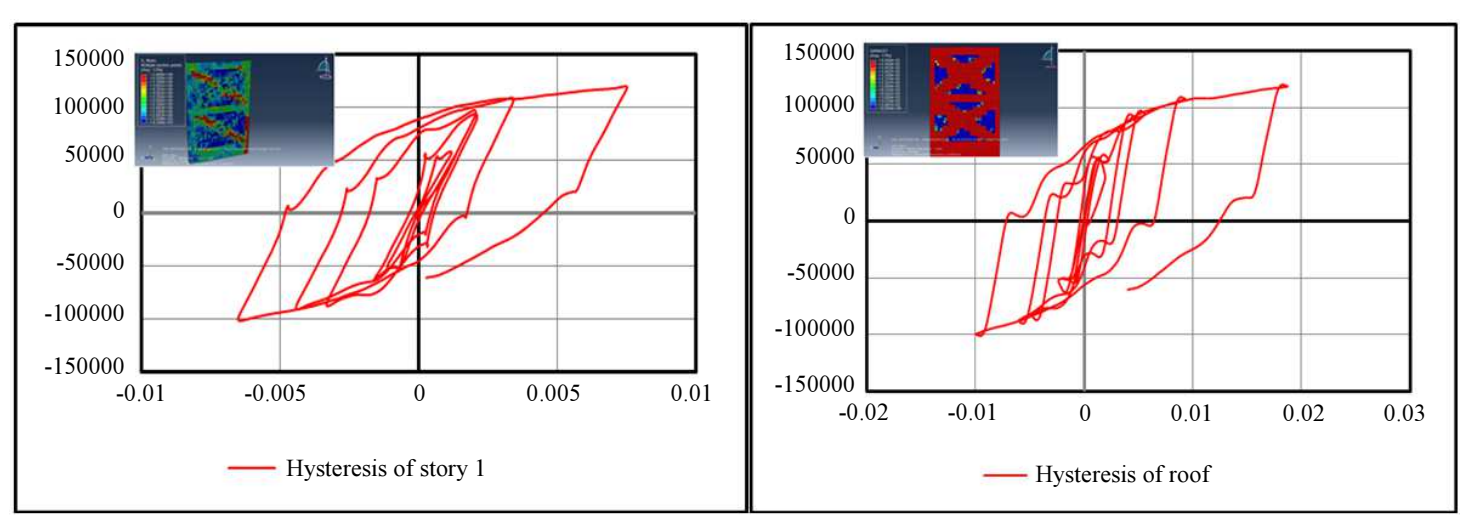

Fig. 13: Hysteresis curve (cycles) of displacement of sample 7
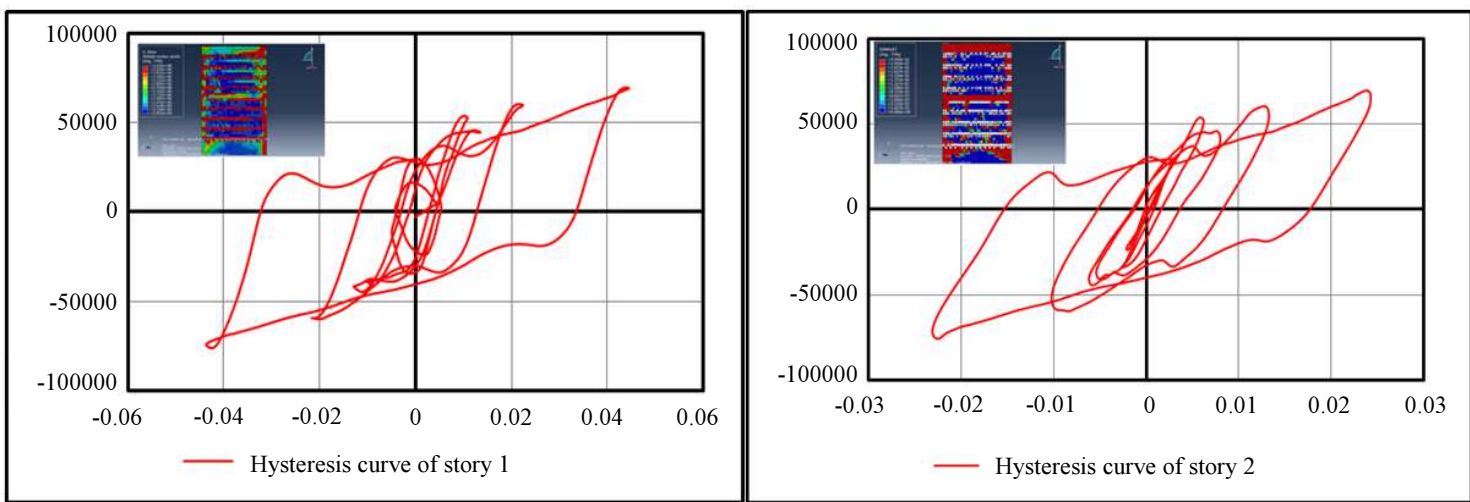

Fig. 14: Hysteresis curve (cycles) of displacement of sample 8
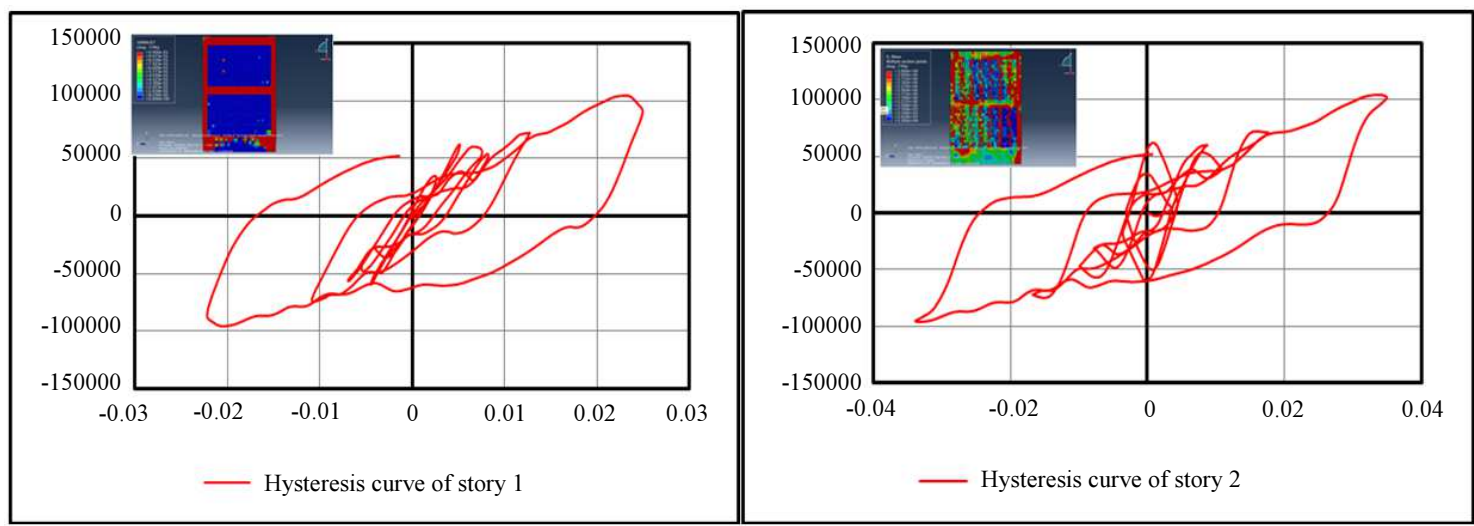

Fig. 15: Hysteresis curve (cycles) of displacement of sample 9

The Fig. 18 shows the addition of polymer sheets for reinforcement improves the load capacity of the frame. Among samples, the sample 11 had the highest bearing capacity due to the use of polymeric carbon sheets in diagonal form While this is lower for sample 3 than for other cases. Also, by examining the lost energy, it can be concluded that among the reinforced samples, the maximum energy dissipated is related to sample 3, which has increased by $75.55 \%$ compared with sample 2 .

Also, in the Fig. 18 the initial stiffness of sample 5 was significantly higher than other samples, which increased by $36.61 \%$ compared to reference sample 2 . Moreover, sample 11 had more load capacity and energy absorption by having 58.62 and 78 , respectively. 


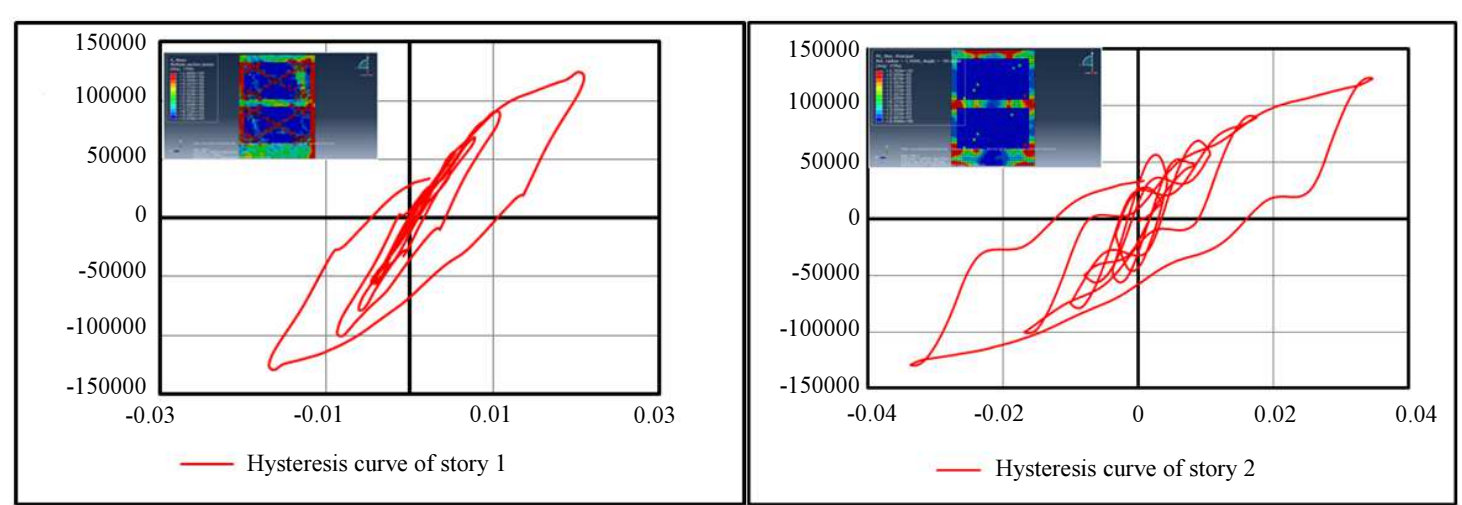

Fig. 16: Hysteresis curve (cycles) of displacement of sample 10
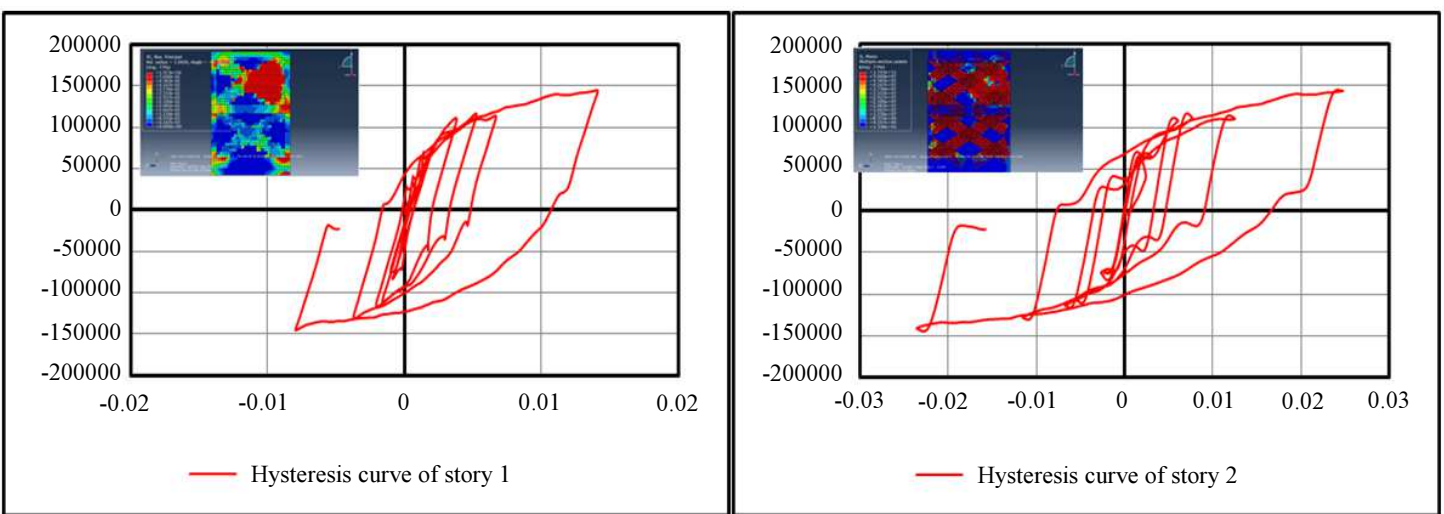

Fig. 17: Hysteresis curve (cycles) of displacement of sample 11

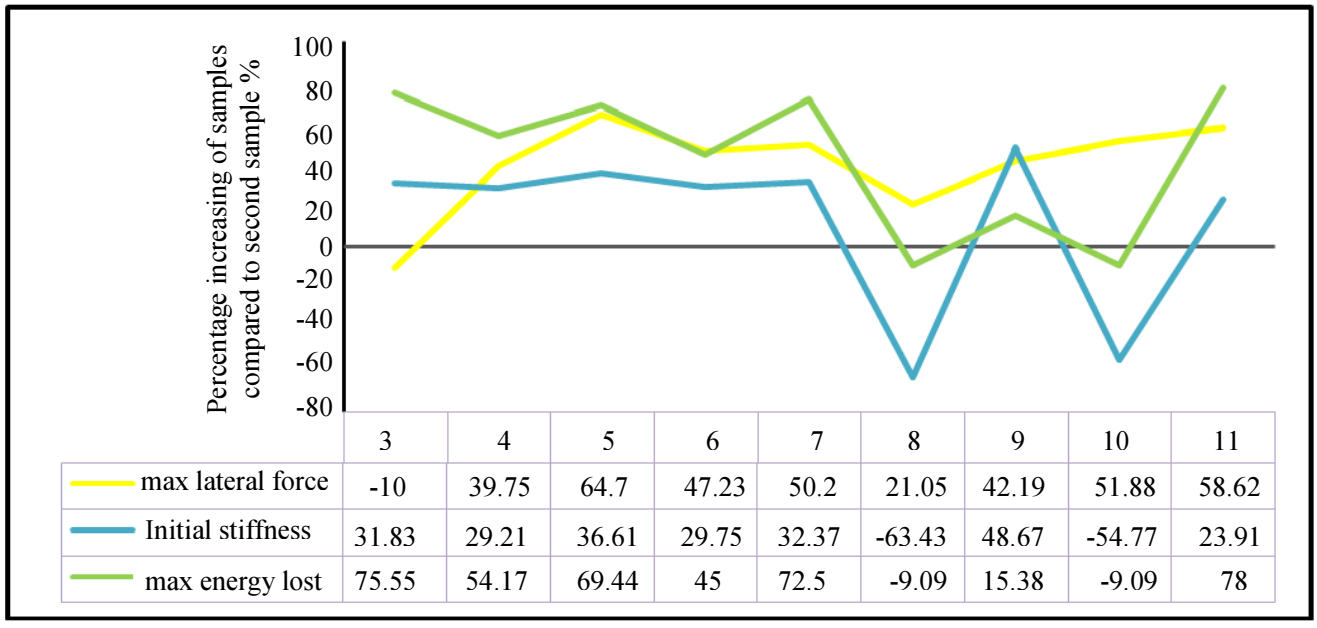

Fig. 18: Summary of finite element results

\section{Conclusion}

The main results of this study are:

- Adding an infill to the frame can dramatically increase the lateral strength and stiffness of the frame, but, reduces the lateral ductility of the frame
- $\quad$ Strengthening masonry infills using CFRP improves its performance significantly and prevents the brittle failure under cyclic loads. By using that lateral load capacity, lateral deformation, formability and amount of energy lost will increase

- By comparing the various configurations of the CFRP layers used for retrofitting infilled frames, it 
is observed that the highest lateral strength and ductility is obtained when the layers are applied to the entire frame and infills. But because of the high price of layers it is not economical

- According to the stress and strain contours of the test samples, it is obvious that the effective performance of the CFRP layers is in the diagonal direction. Because they are subjected to the most stresses in this direction

- Use of lapped splices the base of the column without an anchorage length leads to weak transmission in bars and the retrofitting of them does not fix this defect

- In all retrofited specimens, the internal surface of the hysteresis curve has increased in comparison with initial specimen

- Due to the fact that the performance of retrofitted specimens of the diagonal and diagonal-diamond arrangements are very favorable in terms of resistance, lateral load capacity and economically utilization of CFRF layers, this configuration method is proposed as the best one for strengthening of damaged RC buildings

- By comparing the specimens in terms of ductility and ultimate strength, we noticed that sample 11 has favorable conditions but it has a very brittle failure mode

\section{Author's Contributions}

Mojtaba Fallahi, Sajjad Sayyar Roudsari and Mona Haghighifar: Performed modeling with ABAQUS software and data analysis. Also, participated in writing the manuscript.

Rahmat Madandoust: Provided the research topic and guided the research development, experimental plan and data analysis. Also, participated in writing the manuscript.

\section{Ethics}

This article is an original research paper. There are no ethical issues that may arise after the publication of this manuscript.

\section{References}

ABAQUS, 2012. ABAQUS analysis user's manual documentation. Version 6.12.

ACI, 1988. ACI committee 318, building code requirements for structural concrete (ACI 95). Americam Concrete Institute, Detroit.

Albert, M.L., A.E. Elwi and J.J.R. Cheng, 2001. Strengthening of unreinforced masonry walls using FRPs. J. Compos. Constr., 5: 76-84.

DOI: 10.1061/(ASCE)1090-0268(2001)5:2(76)
Almusallam, T.H., Y.A. Al-Salloum, S.H. Alsayed and A.S. Mosallam, 2001. Behavior of unreinforced masonry walls strengthened with FRP composite materials. Proceedings of the Symposium, Society for the Advancement of Material and Process Engineering, (MPE' 01), Long Beach, Calif.

Babatunde, S.A., 2017. Finite element analysis of FRP strengthened masonry walls subjected to in-plane loading. Sci. Res., 5: 23-35. DOI: $10.11648 /$ j.sr.20170503.12

Drucker, D.C. and W. Prager, 1952. Soil mechanics and plastic analysis for limit design. Quarterly Applied Matth., 10: 157-165. DOI: 10.1090/qam/48291

Akin, E., E. Canbay, B. Binici and G. Ozcebe, 2011. Testing and analysis of infilled reinforced concrete frames strengthened with CFRP reinforcement. J. Reinforced Plast. Compos., 30: 1605-1605. DOI: 10.1177/0731684411424631

Ehsani, M.R., H. Saadatmanesh and J.I. VelazquezDimas, 1999. Behavior of retrofitted URM walls under simulated earthquake loading. J. Compos. Constr., 3: 134-142. DOI: 10.1061/(ASCE)1090-0268(1999)3:3(134)

El-Dakhakhni, W.W., A.A. Hamid, Z.H.R. Hakam and M. Elgaaly, 2006. Hazard mitigation and strengthening of unreinforced masonry walls using composites. Compos. Structures, 73: 458-477.

DOI: 10.1016/j.compstruct.2005.02.017

El-Dakhakhni, W.W., A.A. Hamid and M. Elgaaly, 2004. Seismic retrofit of concrete-masonry-infilled steel frames using glass fiber reinforced polymer laminates. J. Structures Eng., 130: 1343-1352. DOI: 10.1061/(ASCE)0733-9445(2004)130:9(1343)

El-Diasity, M., H. Okail, O. Kamal and M. Said, 2015. Structural performance of confined masonry walls retrofitted using ferrocement and GFRP under inplane cyclic loading. Eng. Structures, 94: 54-69. DOI: $10.1016 /$ j.engstruct.2015.03.035

Erol, G. and F.H. Karadogan, 2016. Seismic strengthening of infilled reinforced concrete frames by CFRP. Compos. B, 91: 473-491. DOI: 10.1016/j.compositesb.2016.01.025

Ozcebe, G., U. Ersoy, T. Tankut, E. Erduran and R.S. Orkun Keskin et al., 2003. Strengthening of brickinfilled RC frames with CFRP. Department of Civil Engineering, Middle East Technical University, Ankara Turkey.

Kaushik, H.B., D.C. Rai and S.K. Jain, 2007. Stress strain characteristics of clay brick masonryunder uniaxial compression. J. Mater. Civil Eng.

Lubliner, J., J. Oliver, S. Oller and E. Onate, 1989. A plastic-damage model for concrete. Int. J. Solids Structures, 25: 299-329.

DOI: $10.1016 / 0020-7683(89) 90050-4$ 
Kachlalev, D. and T. Miller, 2001. Finite element modeling of reinforced concrete structures strengthened with FRP laminates. Final Report, SPR 316, for Oregon Department of Transportation Research Group and Federal Highway Adminstration.

Kent, D.C. and R. Park, 1971. Flexural members with confined concrete. J. Structural Divis., 97: 1960-1990.

Park, R.L., R. Park and T. Paulay, 1975. Reinforced Concrete Structures. 1st Edn., John Wiley and Sons, New York, ISBN-10: 0471659177, pp: 769.

Pour Aminian, M., 2008. Seismic evaluation of historical building in the term of case study of Ali-Shah building at Tabriz. MSc Thesis, Tarbiat Modares Uiversity, Tabriz, Iran.

Sakr, M., S.R. El-khoriby, A.A. Seleemah and E.A. Darvish, 2017. FE modeling of CFRP-retrofitted RC frames with masonry infill walls. Civil Eng. J., 3: 267-286.

Roudsari, S., S. Hamoush, S. Soleimani, T. Abu-Lebdeh and M. HaghighiFar, 2018. Analytical study of reinforced concrete beams strengthened by FRP bars subjected to impact loading condition. Am. J. Eng. Applied Sci. DOI: 10.3844/ofsp.11916
Shahbazi, R. and M. Yekrang Nia, 2013. The guidance of using ABAQUS including civil engineering problems. Civil Science, Tehran.

Soleimani, S.M and S. Sayyar Roudsari, 2015. Analytical study of rinforced concreete beams tested under impact loading. Proceedings of the 5th International Workshop on Performance, Protection and Strengthening of Structures Under Extreme Loading, (UEL' 15), pp: 620-627.

Triantafillou, T.C., 1998. Strengthening of masonry structures usingepoxy-bonded FRP laminates. J. Compos. Constr., 2: 96-104.

DOI: 10.1061/(ASCE)1090-0268(1998)2:2(96)

Sonuvar, M.O., 2001. Hysteretic response of reinforced concrete frames repaired by means of reinforced concrete infills. Ph.D. Thesis, Department of Civil Engineering, Middle East Technical University. 